\title{
AN APPLICATION OF THE HYDRAULIC OSCILLATOR TO FLOWRATE METER
}

\author{
Shizuro Konami*, Teruyuki Maeda** \\ *Dept. of Aeronautical Engineering \\ The National Defense Academy \\ Yokosuka, Japan \\ **Faculty of Engineering \\ Seikei University \\ Tokyo, Japan
}

\section{ABSTRACT}

This paper discusses an applicaton of the hydraulic oscillator utilizing the self -exited vibration phenomenon to a flowrate meter which detects the flowrate in the form of a vibratory member frequency.

The hydraulic oscillator is constituted not to cause the pulsation of the flowrate when the fluid passes through it, and the frequency characteristics are improved to confom with a flowrate meter.

The approximated equations of motion for the vibratory member are obtained and solved by means of digital computer.

The experiments are conducted by varying the ratio of a main spring constant to an auxiliary spring constant. The experimental frequency characteristics almost agree with the theoretical. It is confirmed by the theoretical and experimental study that the hydraulic oscillator is applicable to a flowrate meter.

\section{KEY WORDS}

Oscillator, limit cycle, flowrate meter.

\section{NOMENCLATURE}

a:throttling area in influx port.

A: influx port area.

c:viscous damping coefficient of vibratory member.

$C_{d}$ :discharge coefficient.

D:viscous damping coefficient of damper

$\mathrm{f}:$ frequency $[\mathrm{Hz}]$

$\overline{\mathrm{f}}$ : nondimensionalized frequency.

$f_{x}$ :axial force on vibratory member.

F: axial fluidic force on vibratory member.

$\mathrm{K}$ : spring constant, subscripts 1,2 mean main and auxiliary spring respectively.

$L$ :damping length in valve chamber.

$\mathrm{m}$ :mass of vibratory member.

$m_{d}$ :mass of damper piston.

$\mathrm{N}_{\mathrm{X}}$ : nondimensional factor $\mathrm{N}_{x}=\mathrm{X}_{1} / \mathrm{X}_{0}$

$\mathrm{N}_{\mathrm{K}}$ : nondimensional factor $\mathrm{N}_{\mathrm{K}}=\mathrm{K}_{2} / \mathrm{K}_{1}$

$P_{v}$ :pressure difference between just upper location and the just down location of throttle in valve chamber

Q: flowrate passing through oscillator.

$\mathrm{R}$ : radius of vibratory member.

$S$ : sectional area of flow path in valve chamber

$V$ :velocity of fluid

$\mathrm{X}$ : nondimensionalized displacement $\mathrm{X} / \mathrm{X}$ 。

$X_{1}, X_{0}$ : reference length, see $F i g .1$.

$\alpha, \beta$ :damping coefficient of nondimensiona-

lized equations of motion.

$\rho$ :density of working oil

Subscripts I and II are denotations corresponding to valve chambers I, II respectively.

\section{INTRODUCTION}

In the previous reports ${ }^{(1)}$ () , we presented the theoretical and experimental characteristics regarding to the various types of the hydraulic oscillator which utilized the unsteady flow (anti-damping fluidic force) coming to the change of the influx port area. Those oscillators ${ }^{5) \sim 6}$ have been developed with aiming to make use of it as a servo-valve in hydraulic vibratory machines such as a pile driver, rock drill because they are advantageous due to power amplification ability and strong durability while being placed under strenuous applications.

In these hydraulic oscillators, the oscillator with a dead zone restoring force shows the characteristics ${ }^{3)}$ 4) that the frequencies increase remarkably corresponding to the increase of influx flowrate into the valve chamber. Then, the oscillator may be applied to a flowrate meter which detects the flowrate in the form of a vibratory member frequency.

This paper discusses an application of the hydraulic oscillator to a flowrate meter. For the purpose of detecting the flowrate of oil through the oscillator, it is constituted not to cause the pulsations of flowrate when the fluid passes through it. Moreover, it is reformed to conform with a flowrate meter by reinforcing the restoring force at the adequate displacement of the 
590

vibratory member.

The approximated equations of motion are derived for the hydraulic oscillator aiming the detection of flowrate, and they are computed by means of digital computer. Then, it is confirmed that the experimental frequency characteristics almost agree with the theoretical.

2. ANALYSIS ON THE FREQUENCY CHARACTERISTICS OF THE HYDRAULIC OSCILLATOR.

2.1 Basic Equations of the Oscillator Aiming the Detection of Flowrate

Fig. 1 shows the schematic illustration of the hydraulic oscillator aiming the detection of flowrate. The vibratory member shaping a spool is movable right and left on the ball slide bearings. As the vibratory member is located at a neutral position, both the opening areas of the port 1 and port 2 are the same. The supplied oil flows into the valve chambers and it collides with side walls $w$ and flows out from the drain ports 3 .

Letting the vibratory member move right from the neutral position as an initial condition, the opning area of the port $1 \mathrm{dec}^{-}$ reases while the opening area of port 2 increases. Then, the fluidic anti-damping force to promote the motion acts on the vibratory member because the momemtum-rate of oil inside the valve chambers produces.

When the vibratory member moves to the definite length $X_{0}$, a tip of the vibratory member contacts with a damper of which the spring force is reinforced at the damper displacement $Y$. It is given the damping force and restoring force by the damper and it soon after turns to another direction, and then, it gives rise to a self-exited vibration.

The pulsaions of flowrate through the oscillator scarcely occur because the sum of the influx port areas is a constant during the movement of the vibratory member.

Let us denote the vibratory member mass, the damping coefficient, the displacement and the axial force acting on the vibratory member by $m, c, X$ and $f_{x}$ respectively. Then, the equation of motion for the vibratory member is described by

$$
m \ddot{x}+c \dot{x}=f_{x}
$$

Neglecting the effects of the oil compressibility inside the valve chamber and the frictional loss of the oil, we apply the momemtum theory" to the valve chamber I and II. Then, the axial fluidic force $F$ on the vibratory member is described by

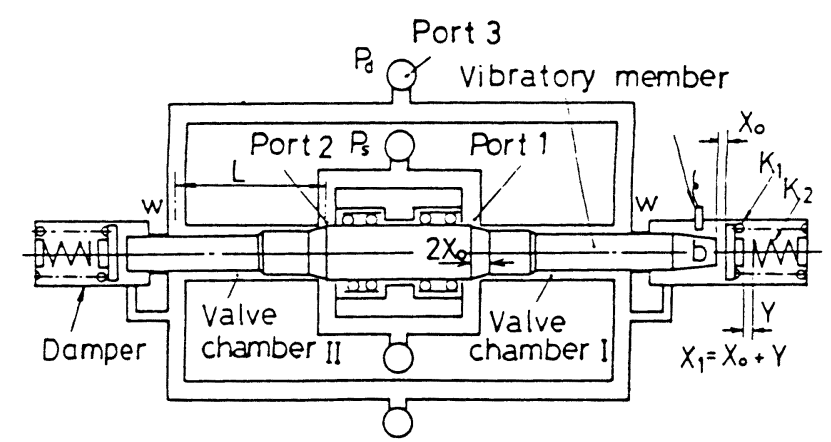

Fig.1 Hydraulic oscillator

$$
\begin{aligned}
F= & -\iint_{C S I} V(\rho V) d A-\iint_{C S I} V(\rho V) d A \\
& -\frac{d}{d t} \iiint_{C V I} V(\rho d V)-\frac{d}{d t} \iiint_{C V I} V(\rho d V)
\end{aligned}
$$

where $\mathbf{V}, A$ and $d v$ are fluid velocity, contorol surface area and the infinitesimal volume inside the valve chamber respectively. Subscripts I and II are denotations corresponding to the valve chambers I, II respectively

(A) Equation of motion on condition that the displacement $|X|$ is smaller than $X_{0}$. The opening areas $A_{1}, A_{I I}$ and throttling areas $a_{1}, a_{I}$ are as follows.

$$
\left.\begin{array}{l}
A_{1}=2 \pi R\left(X_{0}-X\right) \\
a_{I}=2 \pi R\left(X_{0}-X\right) \sin \psi \\
A_{I I}=2 \pi R\left(X_{0}+X\right) \\
a_{I I}=2 \pi R\left(X_{0}+X\right) \sin \psi
\end{array}\right\}
$$

where the length $X_{0}$ is the same as opening distance of influx ports at a neutral point of the vibratory member and $2 \psi$ is the taper angle of the vibratory member at the influx port as shown in Fig. 2 .

Assuming that the pressure loss in pipe lines from an influx port to a drain port is negligible and the opening area is remarkably larger than the throttling area, the oil flowrates $Q_{I}$ and $Q_{I I}$ are described by

$$
\begin{aligned}
Q_{I} & =C_{d} a_{I} \sqrt{2 P_{V} / \rho} \\
& =C_{d} 2 \pi R\left(X_{0}-X\right)(\sin \psi) \sqrt{2 P_{V} / \rho} \\
Q_{I} & =C_{d} 2 \pi R\left(X_{0}+X\right)(\sin \psi) \sqrt{2 P_{V} / \rho}
\end{aligned}
$$

where $P_{v}$ is the pressure difference between the just upper location and the just down location of the throttle in the valve chamber.

The fluidic damping force $F_{1}$ is obtained from the third and forth terms in Eq. (2) by using Eqs. (3)-(6).

$$
\begin{aligned}
F_{1} & =-\frac{d}{d t} \int_{0}^{L}\left(\frac{-Q_{I}}{A_{x}}\right) A_{x} \rho d X+\frac{d}{d t} \int_{0}^{L}\left(\frac{-Q_{I}}{A_{x}}\right) A_{x} \rho d X \\
& =-4 C_{d} \pi R L(\sin \psi) \sqrt{2 P_{V} \rho}(d X / d t)
\end{aligned}
$$

The first and second terms of Eq. (2) denote the fluidic restoring force, then the fluidic restoring force $F_{2}$ is

$$
F_{2}=\left(-\rho Q_{I} V_{I} \cos \varphi+f_{P I}\right)+\left(\rho Q_{I I} V_{I I} \cos \phi-f_{P I I}\right)
$$

where $V_{I} \cos \phi$ and $V_{I I} \cos \phi$ are the axial velocity of oil, and $f_{p}$ is the axial force due to the pressure at the wall w.

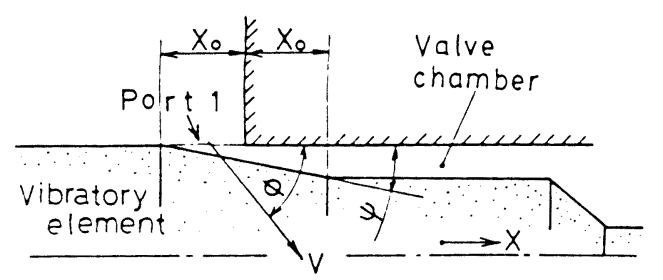

Fig.2 Configuration of vibratory member at the infux port 
Letting the velocities of fluid collided to the walls $w$ denote $V_{a}$, then the force $f_{p}$ and the velocity $V_{a}$ and $V$ are written by

$$
\begin{aligned}
& f_{P I}=\rho Q_{I} V_{a I}, \quad f_{P I}=\rho Q_{\text {II }} V_{a I I} \\
& V_{a I}=Q_{I} / S, \quad V_{a I}=Q_{I I} / S \\
& V_{I}=Q_{I} / A_{I}, \quad V_{I I}=Q_{I} / A_{I I}
\end{aligned}
$$

where $S$ is the sectional area of the flow path in the valve chamber.

By substituting Eqs. (5), (6), (9), (10) and (11) into Eq.(8), fluidic restoring force $F_{2}$ is obtained.

$$
F_{2}=8 C_{d}^{2} \pi R P_{v}\left(\sin ^{2} \psi\right)\left\{\cos \phi-\left(4 \pi R X_{0} / S\right)\right\} X
$$

Axial force $f_{x}$ acting on the vibratory member is

$$
f_{x}=F=F_{1}+F_{2}
$$

The equation of motion is obtained from Eqs. (1), (7), (12) and (13)

$$
\begin{aligned}
& m \ddot{X}+\left(c-4 C_{d} \pi R L \sqrt{2 P_{v} \rho} \sin \psi\right) \dot{X} \\
& +8 C_{d}^{2} \pi R P_{v}\left(\sin ^{2} \psi\right)\left\{\cos \phi-\left(4 \pi R X_{0} / S\right)\right\} X=0 .
\end{aligned}
$$$$
\left(|\mathrm{X}|<\mathrm{X}_{0}\right)
$$

(B) Equations of motion on condition that the displacement $|X|$ is larger than $X_{0}$. When displacement of the vibratory member $|X|$ is larger than the value of $X_{0}$, a thro$t t$ ling area of a influx port closes perfectly while the other throttling area becomes a constant. Therefore, fluidic anti-damping force is zero because the momentum change of oil inside the valve chambers does not exist.

The opening areas and throttling areas of influx port are as follows.

$$
\begin{aligned}
X \geqq X_{0}: & A_{I}=a_{I}=0 \\
& A_{I}=2 \pi R\left(X_{0}+X\right), \quad a_{I}=4 \pi R X_{0} \sin \psi \\
X \leqq-X_{0}: & A_{\square}=a_{I I}=0 \\
& A_{I}=2 \pi R\left(X_{0}-X\right), \quad a_{I}=4 \pi R X_{0} \sin \psi
\end{aligned}
$$

The fluidic restoring forces are obtained from Eqs. (5), (6), (8), (15) and (16).

$$
\mathrm{F}_{2}=16 \mathrm{C}_{\mathrm{d}}^{2} \pi \mathrm{RP}_{v} \mathrm{X}_{0}^{2}\left(\sin ^{2} \psi \cos \phi\right)
$$

$$
\left\{\frac{1}{X+X_{0}(|X| / X)}-\frac{2 \pi R}{S \cos \phi} \frac{|X|}{X}\right\}, \quad\left(|X| \geq X_{0}\right)
$$

When the displacement becomes larger than the value of $X_{0}$, the vibratory member comes into contacts with a damper which has two springs - a main spring and an auxiliary spring. Then the axial force acting on the vibratory member is

$$
\begin{aligned}
f_{x}= & -D \dot{X}-K_{1}\left\{X-X_{0}(|X| / X)\right\}-F_{2}, \quad\left(X_{0} \leqq|X|<X_{1}\right) \\
f_{x}= & -D \dot{X}-\left(K_{1}+K_{2}\right) X-K_{1}\left\{X_{0}\right. \\
& \left.+\left(K_{2} / K_{1}\right) X_{1}\right\}(|X| / X)-F_{2}, \quad\left(|X| \geqq X_{1}\right)
\end{aligned}
$$

Equations of motion are obtained from Eqs. $(1),(17),(18)$ and (19). $\left(m+m_{d}\right) \ddot{X}+(c+D) \dot{X}+K_{1}\left\{X-X_{o}(|X| / X)\right\}$

$$
\begin{gathered}
+16 C_{d}^{2} \pi R P_{v} X_{0}^{2} \sin ^{2} \psi(\cos \phi) \\
\left\{\frac{1}{X+X_{0}(|X| / X)}-\frac{2 \pi R}{S \cos \phi} \frac{|X|}{X}\right\}=0, \\
\left(X_{0} \leqq|X|<X_{1}\right)
\end{gathered}
$$

$\left(m+m_{d}\right) \ddot{X}+(c+D) \dot{X}+\left(K_{1}+K_{2}\right) X-K_{1}\left\{X_{0}\right.$

$$
\begin{gathered}
\left.+\left(K_{2} / K_{1}\right) X_{1}\right\}(|X| / X)+16 C_{d}^{2} \pi R P_{v} X_{0}^{2} \sin ^{2} \psi \\
(\cos \phi)\left\{\frac{1}{X+X_{0}(|X| / X)}-\frac{2 \pi R}{S \cos \phi} \frac{|X|}{X}\right\}=0, \\
\left(|X| \geqq X_{1}\right)
\end{gathered}
$$

Equations of motion (14),(20) and (21) are nondimensionalized as follows.

$$
x^{\prime \prime}-\alpha x^{\prime}+\gamma\left\{\left(m+m_{d}\right) / m\right\}\left\{\frac{1}{2}-\frac{2 \pi R X_{0}}{S \cos \phi}\right\} x=0
$$

$$
(|x|<1)
$$

$$
\begin{aligned}
& \mathrm{x}^{\prime \prime}+\beta \mathrm{x}^{\prime}+\mathrm{x}-(|\mathrm{x}| / \mathrm{x}) \\
& +\gamma\left\{\frac{1}{x+(|x| / x)}-\frac{2 \pi R x_{0}}{S \cos \phi} \frac{|x|}{x}\right\}=0, \quad\left(1 \leqq|\mathrm{x}|<\mathrm{N}_{x}\right) \\
& \mathrm{x}^{\prime \prime}+\beta \mathrm{x}^{\prime}+\left(1+\mathrm{N}_{x}\right) \mathrm{x}-\left(1+\mathrm{N}_{x} \mathrm{~N}_{x}\right)(|\mathrm{x}| / \mathrm{x}) \\
& +\gamma\left\{\frac{1}{x+(|x| / x)}-\frac{2 \pi R x_{0}}{S \cos \phi} \frac{|x|}{x}\right\}=0, \quad\left(\mathrm{~N}_{x} \leqq|\mathrm{x}|\right)
\end{aligned}
$$

where

$$
\begin{aligned}
& \mathrm{x}=\mathrm{X} / \mathrm{X}_{0}, \quad \tau=\omega_{0} \mathrm{t}, \quad \omega_{0}^{2}=\mathrm{K}_{l} /\left(\mathrm{m}+\mathrm{m}_{d}\right) \\
& \mathrm{d}\left[\mathrm{d} / \mathrm{dt}=[]^{\prime}, \mathrm{N}_{\mathrm{K}}=\mathrm{K}_{2} / \mathrm{K}_{1}, \mathrm{~N}_{\mathrm{x}}=\mathrm{X}_{1} / \mathrm{X}_{0}\right. \\
& \alpha=\left(4 \mathrm{C}_{d} \pi \mathrm{RL} \sin \psi \sqrt{2 \mathrm{P}_{v} \rho}-\mathrm{c}\right) /\left(\mathrm{m} \omega_{0}\right) \\
& \beta=(\mathrm{c}+\mathrm{D}) /\left\{\omega_{0}\left(\mathrm{~m}+\mathrm{m}_{d}\right)\right\} \\
& \gamma=16 \mathrm{C}_{d}^{2} \pi \mathrm{RP}_{v} \sin ^{2} \psi(\cos \phi) /\left\{\omega_{0}^{2}\left(m+m_{d}\right)\right\}
\end{aligned}
$$

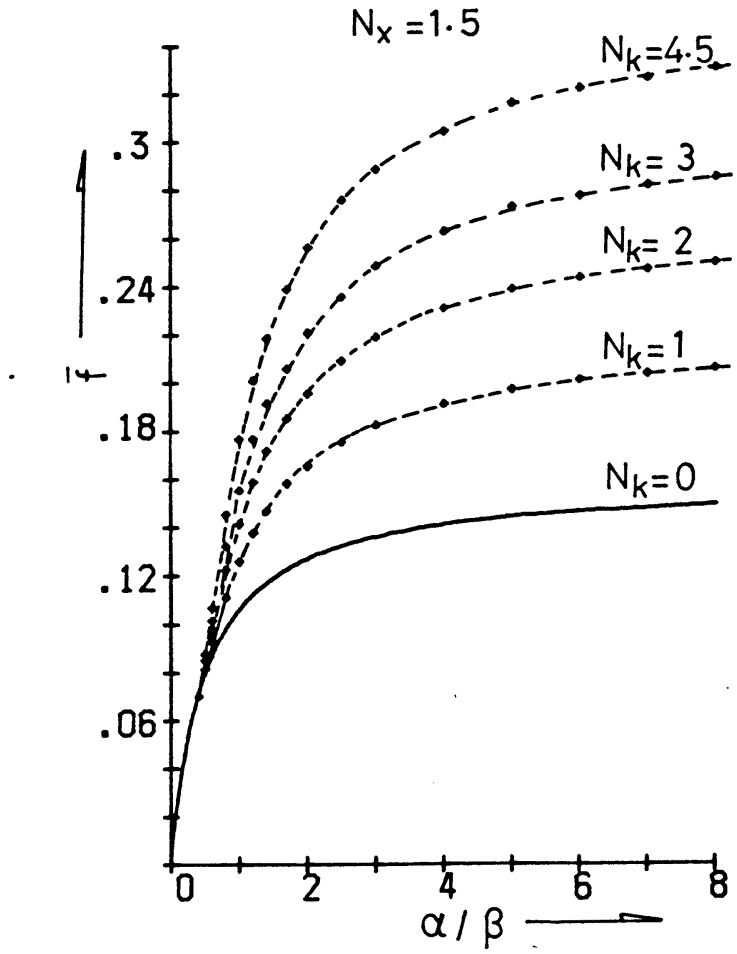

Fig.3 Theoretical frequency characteristics of the oscillator 
2.2 Frequency characteristics of hydraulic oscillator aiming to detect flowrate.

The third term in Eq. (22) is negligible provided that the value of the factor $4 \pi \mathrm{RX}$. $/(S \cos \phi)$ nearly equals to one, and the fifth terms in Eq. (23) and in Eq. (24) are also negligible provided that the value of factor $r$ is roughly smaller than one. Then the equations of motion are approximately denoted by the following equations.

$$
\begin{array}{cc}
x^{\prime \prime}-\alpha x^{\prime}=0, & (|x|<1) \\
x^{\prime \prime}+\beta x^{\prime}+x-(|x| / x)=0, & \left(1 \leq|x|<N_{x}\right) \\
x^{\prime \prime}+\beta x^{\prime}+\left(1+N_{k}\right) x-\left(1+N_{x} N_{k}\right) & (|x| / x)=0,
\end{array}
$$

$$
\left(|x| \geqq N_{x}\right)
$$

In the case that the nondimensionalized amplitude is smaller than the value of the factor $N_{x}$, the characteristic equations of the oscillator are written ${ }^{3}$ by

$$
\begin{aligned}
& \bar{f} \doteqdot(1 / \pi)[(\alpha / \beta) /\{1+2(\alpha / \beta)\}] \\
& x_{m} \doteqdot 1+(4 / \pi)(\alpha / \beta)
\end{aligned}
$$

where $x_{m}$ is the nondimensionalized amplitude $\left(x_{m}=A_{m} / x_{0}, A_{m}\right.$ :amplitude), and the value of the factor $\beta$ is assumed to be less than 0.5 The factor $\alpha / \beta$ is obtained as a function of folwrate $Q$ from Eqs. (5), (6) and(25).

$$
\alpha / \beta=\left(m+m_{d}\right)\left\{\left(\rho L / X_{0}\right) Q-c\right\} /\{m(c+D)\}
$$

A full line in Fig. 3 shows the frequency characteristics obtained from Eq. (29).

This curve rises rapidly within the range where the value of the factor $\alpha / \beta$ is small.

It is evident from Eq. (29)-(31) and Fig 3 that we had better adopt the large values of the factors $L / X_{0}$ in order to get the good sensitivity for the flowrate detection.

In the case that the nondimensional amplitude exceeds the value of the factor $N_{x}$, the characteristics of the oscillator are

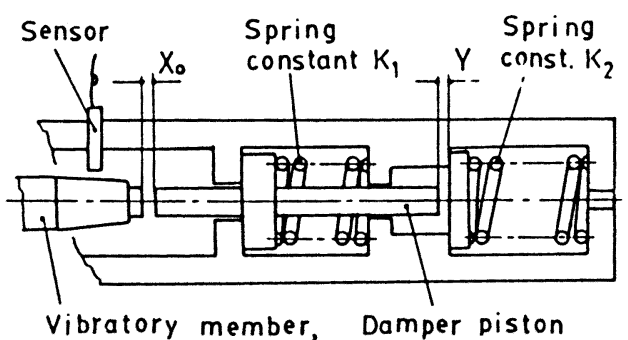

Fig. 4 Configuration of damper

Table 1 Combinations of spring

\begin{tabular}{|l|r|r|}
\hline $\begin{array}{l}\text { Experiment } \\
\text { number }\end{array}$ & $\begin{array}{l}\text { Main spring } \\
\text { constant } K_{1}\end{array}$ & $\begin{array}{l}\text { Aux.spring } \\
\text { constant } K_{2}\end{array}$ \\
\hline No. 1 & $4.47[\mathrm{kN} / \mathrm{m}]$ & $0[\mathrm{kN} / \mathrm{m}]$ \\
\hline No. 2 & $12.7[\mathrm{kN} / \mathrm{m}]$ & $0[\mathrm{kN} / \mathrm{m}]$ \\
\hline No.3 & $4.47[\mathrm{kN} / \mathrm{m}]$ & $25[\mathrm{kN} / \mathrm{m}]$ \\
\hline No. 4 & $12.7[\mathrm{kN} / \mathrm{m}]$ & $25[\mathrm{kN} / \mathrm{m}]$ \\
\hline
\end{tabular}

computed from Eqs. (26)-(28) by means of digital computer and shown in Fig. 3 .

\section{EXPERIMENTAL APPARATUS AND PROCEDURE}

The hydraulic oscillator used in this experiment is the same as shown in Fig.1 except for the portion of a damper. Fig. 4 shows the damping portion of the oscilltor used in this experiment.

The experiments were conducted under the conditions that the temparature of oil was ordinarily $38( \pm 0.5)\left[{ }^{\circ} \mathrm{C}\right]$. Then the effects of the oil temparature on the characteristics of the oscillator were ivestigated in the temparature range from $28\left[{ }^{\circ} \mathrm{C}\right]$ to $48\left[{ }^{\circ} \mathrm{C}\right]$.

The dimensions of the hydraulic oscillator are as follows.

Spool (vibratory member) radius: $R=1[\mathrm{~cm}]$

Valve chamber length : $L=7.8[\mathrm{~cm}]$

$\sin \psi=0.267$, Mass of the spool: $m=0.59[\mathrm{~kg}]$

Mass of the damper piston: $m_{d}=0.07[\mathrm{~kg}]$

Sectional flow path area in valve chamber: $\mathrm{S}=1.6\left[\mathrm{~cm}^{2}\right]$

Spring constant: $K_{1}=4.48[\mathrm{kN} / \mathrm{m}], 12.7[\mathrm{kN} / \mathrm{m}]$

$$
\mathrm{K}_{2}=25[\mathrm{kN} / \mathrm{m}]
$$

Combinations of the springs used in the experiment are shown in Table 1 .

Figure 5 shows the experimental set up. The flowrate passing through the hydraulic oscillator was detected by means of the tachometer which was connected to the gear motor in the experimental circut.

The pressures $P_{2}$ and $P_{3}$ in the experimental circut and vibratory behaviors of the vibratory member were recorded by means of the oscillograph.

The vibration behaviors were detected in the form of the displacement sensor out-

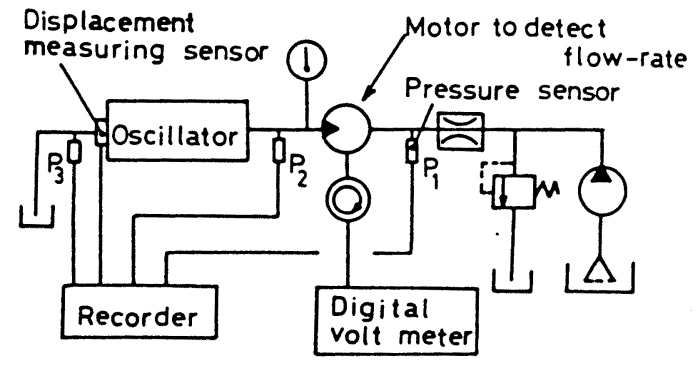

Fig.5 Experimental circut
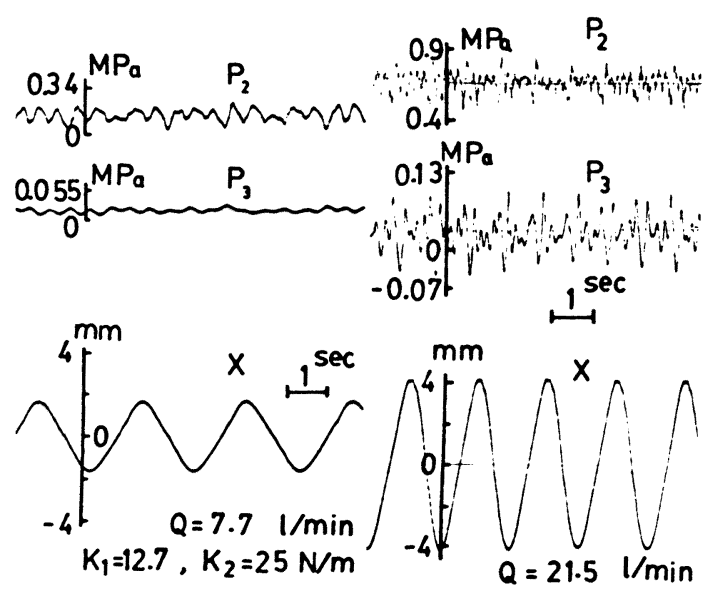

Fig.6 Vibration behavior of vibratory member 
put (voltage) which corresponds with the clearance between the sensor and the truncated side of the vibratory member.

\section{EXPERIMENTAL RESULTS AND DISCUSSIONS}

Figure 6 shows a vibratory behavior of the vibratory member and the pressure fluctuation in circut. The vibratory characteristics of the oscillator were obtained by measuring the amplitudes and frequencies of the vibration waves.

Figure 7 shows the experimental characteristics which relate the frequency of the vibratory member to the flowrate passing through the oscillator.

It is evident from the equations of motion (22)-(25) and Eq. (31) that the hydraulic oscillator does not give rise to self -exited vibration provided the flowrate is so small as to make a negative value of the factor $\alpha$. In the hydraulic oscillator used in this experiment, the minimum flowrate to generate the self-exited vibration is about $4[1 / \mathrm{min}]$.

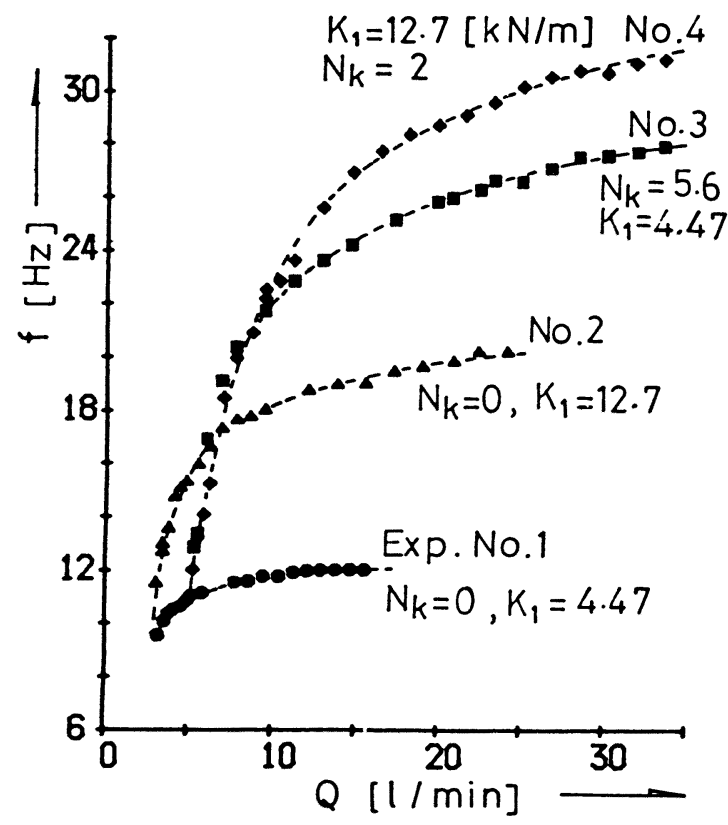

Fig.7 Experimental frequency characteristics of the oscillator

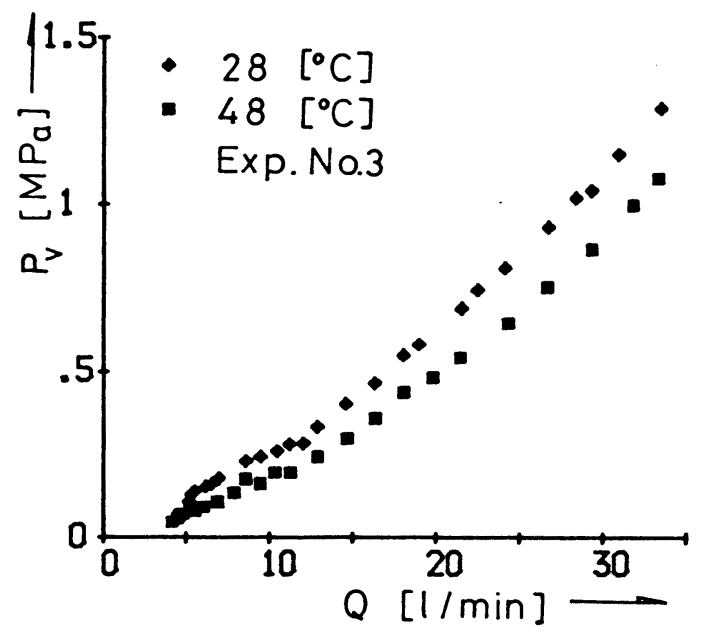

Fig. 8 Pressure drops in the hydraulic oscillator
It is necessary for detecting a smaller flowrate that the oscillator should be designed to make a small positive value of the factor $\alpha_{i}^{\prime} \beta$ - that is, to make a larger value of the factor $L / X_{0}$ and a larger value of the damping factor $D$.

As shown in Fig.7, the frequency change for $N_{K}=0$ becomes large as the value of the spring constant $K_{1}$ becomes large. For that reason, both frequency changes in the $f-Q$ curves No. 3 and No. 4 are comparable.

However, it is the fact that the effect of the factor $N_{K}$ on the frequency change is more significant as the factor $N_{K}$ becomes large. That is, the experimental frequency change for $K_{1}=4.47[\mathrm{kN} / \mathrm{m}]$ increases from 2.8 [Hz] to $16.5[\mathrm{~Hz}]$ by changing the value of the factor $N_{K}$ from 0 to 5.6 , while the frequency change for $K_{1}=12.7[\mathrm{kN} / \mathrm{m}]$ only increases from $9.5[\mathrm{~Hz}]$ to $21[\mathrm{~Hz}]$ by changing the value of the factor $N_{K}$ from 0 to 2.6 .

Figure 8 shows the pressure drops that produce as the oil passes through the hydraulic oscillator at the temparature $28\left[{ }^{\circ} \mathrm{C}\right]$ and $48\left[{ }^{\circ} \mathrm{C}\right]$. Though the pressure drops slightly decrease by the rise of oil temparature, the $f-Q$ characteristics are hardly affected by the rise of the oil temparature as shown in Fig.9.

The experimental amplitude-frequency characteristics are compared with the theoretical in Fig.10. In the case that the value of the factor $N_{K}$ is zero, the theoretical curve is obtained by eliminating the factor $\alpha / \beta$ from Eqs. (29) and (30). The theoretical curves for the other cases are obtained by digital computer analysis of Eqs. (26), (27) and (28) of which coefficients $\alpha$ and $\beta$ are systematically varied. As shown in Fig.10, the nondimensionalized experimental frequency characteristics almost agree with the theoretical though the experimental frequencies are slightly smaller than the theoretical. It is caused by neglecting the fludic restoring force in equations of moion that the theoretical frequencies are slightly larger than the theoretical.

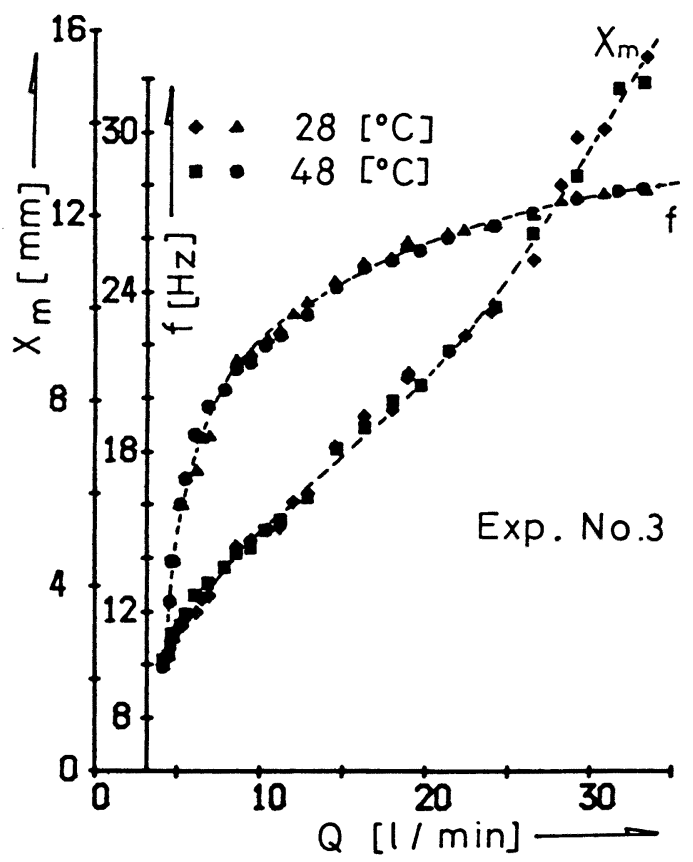

Fig.9 Experimental characteristics of the hydraulic oscillator 
The nondimensionalized restoring force $f_{\mathrm{T}}$ containing in Eqs. (22), (23) and (24) is as follows

$$
\begin{array}{r}
f_{r}=\gamma\left\{\left(m+m_{d}\right) / m\right\}\left\{\frac{1}{2}-\frac{2 \pi R X_{0}}{S \cos \phi}\right\} x, \quad(|x|<1) \\
f_{r}=x-\frac{|x|}{x}+\gamma\left\{\frac{1}{x+(|x| / x)}-\frac{2 \pi R X_{0}}{S \cos \phi} \frac{|x|}{x}\right\}, \\
\left(1 \leqq|x|<N_{x}\right)
\end{array}
$$

$\mathrm{f}_{\mathrm{T}}=\left(1+\mathrm{N}_{\mathrm{K}}\right) \mathrm{x}-\left(1+\mathrm{N}_{\mathrm{x}} \mathrm{N}_{\mathrm{K}}\right)(|x| / \mathrm{x})$

$$
+\gamma\left\{\frac{1}{x+(|x| / x)}-\frac{2 \pi R x_{0}}{S \cos \phi} \frac{|x|}{x}\right\}, \quad\left(|x| \geqq N_{x}\right)
$$

Equation (32) and the last terms of Eqs. (33) and (34) denote the fluidic restoring force.

Fig.11 shows the comparision of the restoring force $f_{t}$ with the approximated restoring force $f_{T a}$ which neglects the fluidic restoring force. In computing the restoring force, the coefficient $C_{d}$ and an angle $\phi$ are

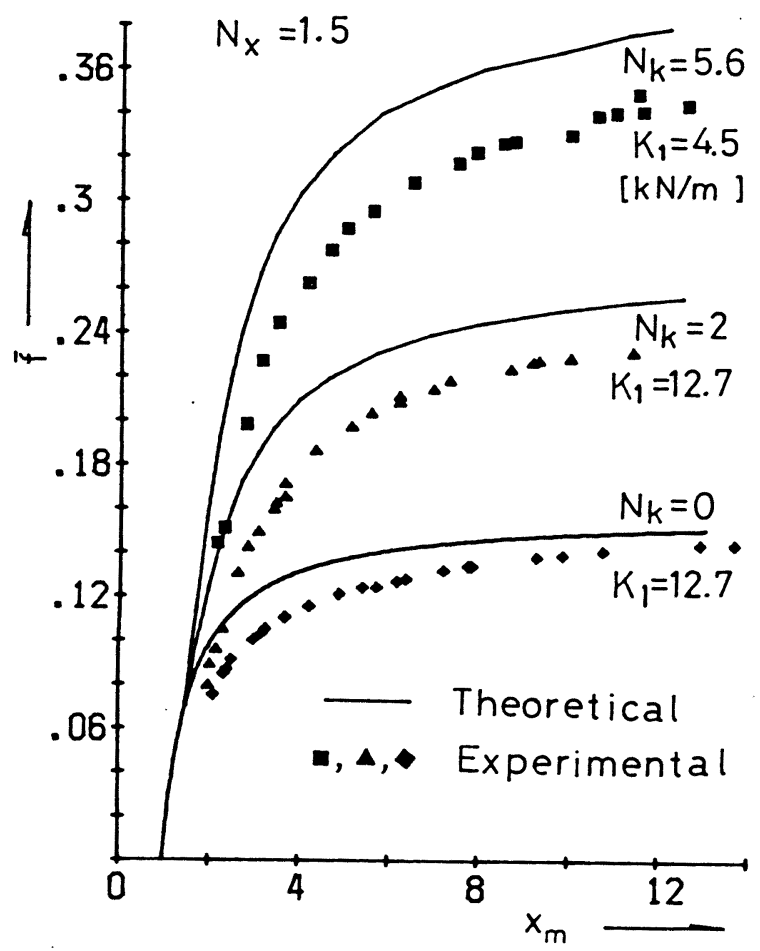

Fig.10 Comparision of the experimental characteristics with the theortical

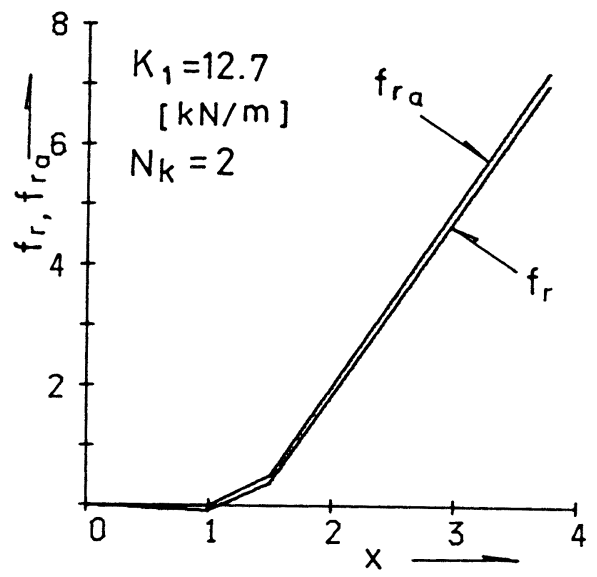

Fig.11 Nondimensional restoring force in equation of motion assumed to be 0.9 and 69 [degree] respec tively, and the value of the pressure diff erence $P_{V}$ is assmued to be 0.6 [MPa] which is a mean value in the experiments.

As shown in Fig.11, the approximated restoring force in equations of motion (26). (27) and (28) are more largely estimated than the original. This is a reason that the theoretical frequencies are slightly larger than the experimental in Fig. 10 .

In these experiments, the hydraulic oscillator gave rise to the self-exited vibration of which nondimensionalized amplitu des were not less than 2. Therefore, it is considered that the frequency changes in the $f-Q$ characteristics more increase by set $t$ ing the auxiliary spring at the location where the distance $Y$ is about the value of $2 \mathrm{X}_{0}$.

\section{CONCLUSIONS}

An application of the hydraulic oscillator to a flowrate meter has been discussed theoretically and experimentally. The experimental characteristics of the hydraulic oscillator almost agree with the theoretical. It is confirmed that the hydraulic oscillator is utilizable for flowrate meter by improving the former oscillator so as to conform with it. That is, it is necessary for a hydraulic oscillator aiming to detect the flowrate that the proper set position of springs, the adequate combination of springs and the advisable sizes of the oscillator elements are given in order to get good sensitivity, and moreover it should be designed not to pulsate the flowrate of oil passing through it.

\section{REFERENCES}

(1) Maeda, T: Studies on Hydraulic Oscillator (1st Report, Theoretical Analysis ) Japan so.Mechanical Engrs. (in japanese), Vol.44 No. 377, 1987-1,pp. 109-116.

(2) Maeda, T.,Konami, S: Studies on Hydraulic Oscillator(2nd Report, Experimental Analysis ), Bull.JSME, Vol.24, No.187, 1981-1. pp. 117-123.

(3) Konami,S.,Maeda, T: A Study on Hydraulic Oscillator with Low Frequency Characteristics(1st Report, Theoretical Analysis) J.Japan Hydraulics \& Phneumatics Soc. (in japanese), Vol . 16, No. 3, 1985-9, pp. 448-455.

(4) Konami, S., Maeda, T:A Study on Hydraulic Oscillator with Low Frequency Characteristics(2nd Report, Experimental Analysis) J. Japan Hydraulics \& Phneumatics Soc. (in japanese), Vol . 18, No . 4, 1987-7, pp. 307-312.

(5) Konami,S.,Maeda, T:Studies on Hydraulic Oscillator(3rd Report, Theoretical analysis of the Oscillator with a Srvo-valve Mechan ism), Bu l l. JSME, Vol . 25, No . 201, 19823, pp. 380-386.

(6) Konami,S.,Maeda, T:Studies on Hydraulic Oscillator(4th Report,Eperimental analysis of the Oscillator with a Srvo-valve Mechanism), Japan so.Mechanical Engrs. (in japanese), Vol.47, No.422,1981-10,pp. 297-305.

(7) Blackburn, J.F: Fluid Power Control,MIT. Press. , 1960,pp. 297-305 